\title{
Iranian Women's Experiences of Health Information Seeking Barriers: A Qualitative Study in Kerman
}

\author{
Alireza Nikbakht Nasrabadi ${ }^{1}$; Sakineh Sabzevari ${ }^{2}$; Tayebeh Negahban Bonabi ${ }^{3,}$ \\ ${ }_{2}^{1}$ Department of Medical Surgical Nursing, School of Nursing and Midwifery, Tehran University of Medical Sciences, Tehran, IR Iran \\ ${ }^{2}$ Department of Medical Sergical Nursing, School of Nursing and Midwifery, Kerman University of Medical Sciences, Kerman, IR Iran \\ ${ }^{3}$ Department of Community Health Nursing, School of Nursing and Midwifery, Kerman University of Medical Sciences, Kerman, IR Iran \\ ${ }^{*}$ Corresponding Author: Tayebeh Negahban Bonabi, Department of Community Health Nursing, School of Nursing and Midwifery, Kerman University of Medical Sciences, Kerman, \\ IR Iran. Tel: +983434255900, Fax:+983434258497, E-mail: negahbant@yahoo.com
}

Received: November 6, 2014; Revised: November 29, 2014; Accepted: December 31, 2014

\begin{abstract}
Background: Women as active health information seekers play a key role in determining lifestyle and possible implementation of preventive measures, thereby improving the health of individuals, families and society. Although studies indicate that equipping people with adequate health information leads to optimal health outcomes, sometimes the complexity of human behavior and presence of barriers and limitations expose them to challenges.

Objectives: This study was designed to explore women's experiences of health information seeking barriers.

Patients and Methods: In this qualitative content analysis study, data collection was conducted regarding inclusion criteria, through purposive sampling and semi-structured interviews with 17 women and using documentation and field notes until data saturation. Qualitative data analysis was performed constantly and simultaneously with data collection.

Results: Five central themes were emerged to explain women's experiences of barriers to health information seeking as inadequate support from health care system, shame and embarrassment, costs, wrong ideas and beliefs and inadequate health literacy.

Conclusions: It seems the accurate and evidence-based review of the current health system is crucial to support the health informative requirements in a community-based approach, respecting the community cultural-religious beliefs and client participation in health care and according to local resources.
\end{abstract}

Keywords: Women; Health; Lifestyle; Health information; Seeking; Barriers

\section{Background}

Today, health is considered the basic need and right of all humans, and quality of people's health, equitable distribution of health among different social strata and protection of disadvantaged people against health risk factors are indicators of development in any society (1). Furthermore, the advent and dominance of information and communication era, subsequent rise in available information, and increasing attention to and emphasis on patient participation in health care (2), and the importance of self-care $(3,4)$ led to renewed health care systems interest to predict factors influencing health promotion, preventive behaviors incidence, lifestyle reform and consequently emphasis and focus on health information seeking behaviors $(5,6)$. In this context, information literacy and subsequent correction of people's health information was considered one of the objectives of Healthy People 2020 in the United States (7). Furthermore, improving health information, accountability, empowerment and active and structured participation of individuals, families and community in providing, maintaining and promotion of health, using the capacity of cultural, educational institutions and media, supervised by the Ministry of Health and Medical Education are listed among the priorities in the strategic document of policies of the Health System of Islamic Republic of Iran. Healthcare specialists reported that equipping people with adequate health information would help achieving optimal health outcomes (8-10), including better adjustment, less stress, the ability to make better medical decisions, modifying self-care (11), greater social support and achieving appropriate changes in lifestyle (12). Moreover, health information seeking behaviors can form the basis for judgments, beliefs and attitudes on healthy behaviors, and lead to acquiring sufficient knowledge to recognize alternatives, available resources for taking different actions and weighing up pros and cons (13). Thus, in the absence of adequate health information, it can be anticipated that patients would be seriously involved with too many concerns and expectations, which may incur waste of time and money and cause irrelevant, or longer and more complex medical consultations and treatments. According to literature, many studies reported the key role of health informationseeking in dealing with health challenges (14-18). Yet, results of some studies indicated complexities of human behavior in this context, and sometimes people's lack of active involvement (19), barriers and limitations to access 
(20), and even limitations in patients' understanding of health information $(19,21)$. This study focused on women health information seeking behaviors because according to studies, women are active health information seekers (22-24), and in some papers, they have been introduced as the family health goalkeeper. While taking care of family members' health, they play a key role in determining family lifestyle (22). They also pay more attention to their own health than men and probably consider preventive measures more often $(8,25,26)$.

\section{Objectives}

This study was designed to explore women's health information seeking barriers to help healthcare providers design health information providing systems according to women's preferences, needs and perceived barriers with a clear understanding of existing barriers to seeking health information in Iranian women.

\section{Patients and Methods}

This study was conducted with a qualitative approach, using conventional content analysis. Qualitative content analysis is an appropriate method to obtain variable and reliable results from textual data. This method is used to create new knowledge and ideas and provides facts and guidelines. This method aims to condense a broadly described phenomenon, with achievements of concepts or descriptive classes of the phenomenon (27). The present study is part of a large study using the grounded theory. In this study, participants were 17 women purposefully selected from rural and urban health centers, organizations associated with women's affairs, parks and offices of Rafsanjan city in Iran. Inclusion criteria were middle-aged married Iranian women, with the ability to communicate well and desire to take part in study, with favorable physical, mental and cognitive conditions for sharing their experiences. Generally, participants were selected from a diverse range for age, education, occupation, place of residence (rural, urban), health status, etc. For purposive, maximum variation sampling, the researchers looked for key informant women who could provide broad insight about the research question, through friends, colleagues and health care providers. Following approval of the project by the Research Deputy of Kerman University of Medical Sciences (No 93/10/60/24158), semi-structured interviews were conducted by a research team member, familiar with interviewing techniques. Sampling continued until saturation of data. All participants who were invited for the interview accepted the invitation and remained until the end of study. The interviews were conducted after agreement on time and place between the interviewer and interviewees, and obtaining consent of eligible participants, in an intimate and relaxed setting. Before the interview, the researcher explained the study objectives and reasons for their selection for interview and participation and clarified benefits of the study for them and healthcare workers and how they could access the results. Then, according to study objectives, subject of research questions and the approach adopted, the researcher posed several possible questions according to the interview guide. To correctly direct the research and according to previous interviews, the interview guide was changed after each interview. Each interview lasted between 45 minutes and 120 minutes. Interviews were conducted at home or workplace of either the researcher (School of Nursing and Midwifery, Rafsanjan) or participants. Interviews were transcribed immediately after completion. Then, recorded interviews were listened several times and typed verbatim in Microsoft Word ${ }^{\circledR}$, which led to researcher's immersion in data. Along with interviews, participants' characteristics were recorded. Furthermore, the researcher attended public Rafsanjan library, and reviewed 10 copies of local and national newspapers, family magazines and columns on medical topics and used them as data. Contents of these topics focused mostly on women's questions and answers about health issues. The researcher also attended health centers and studied educational booklets, pamphlets, CDs, brochures and used them in data analysis. Data was analyzed with an inductive approach by the research team, using constant comparative method as follows; transcribing recorded interviews in Microsoft Word ${ }^{\circledR}$ software and determining meaning units, which included women's statements in interviews and materials obtained from observations, documentations and field notes on barriers to women's health information seeking, coding and labeling meaning units, review of codes with interview text and information obtained from other sources, revision and comparison of codes for similarities and differences, merging similar codes and categorization, development of categories according to similarity and suitability, revision and comparison of categories according to data to ensure rigor of codes, and finally, identification of themes associated with women's health information seeking barriers $(28,29)$. To ensure the accuracy and reliability of qualitative data, standards of scientific rigor were applied including credibility, dependability, transferability and confirm ability, as proposed by Guba and Lincoln (30). To ensure credibility of data, prolonged involvement (over a year), triangulation in data collection (field notes, transcriptions, interviews and documentations), peer check and constant comparison were used. Member check was used to assess dependability of data (to ensure stability and reliability of data). To this end, comments from colleagues familiar with qualitative approach and review of participants' transcriptions were used. These and field notes were also presented to two nursing professors to ensure confirmability of results. Transferability was provided by rich description of data.

\subsection{Ethical Considerations}

This study was conducted with the permission of Ethics in Research Committee of Kerman University of Medical 
Sciences, code No 93/133. Principles of ethics in research were considered including informed consent, anonymity, confidentiality and participants' rights to withdraw from the study at any time. Moreover, study objectives, confidentiality of data and recording of interviews were explained to participants prior to interviews, and their verbal consents were obtained.

\section{Results}

Seventeen married women, aged 25 to 60 years participated in this study, of whom 5 were housewives, 10 were employees and 2 were self-employed. Six women lived in villages and the rest were city dwellers. Six participants had known diseases and were receiving treatment and the rest appeared healthy. Two interviews were held in participants' private homes, one in researcher's home, two at participants' workplace and twelve at researcher's office at Rafsanjan School of Nursing and Midwifery. Table 1 represents characteristics of participating women.

Analysis of data led to five themes as women's health information seeking barriers, including: 1) inadequate support from health care system, 2) shame and embarrassment, 3) costs, 4) wrong ideas and beliefs and 5) inadequate health literacy.

\subsection{Inadequate Support From Health Care System}

The theme of inadequate support from health information seeking behaviors was observed in different forms in almost all participants. Sub-categories of this theme included "performance of health service providers" and "conditions governing provision of health services".

\subsubsection{Performance of Health Care Providers}

According to analysis of data, most women considered performance of health care providers in meeting their information needs as inadequate. In their view, healthcare providers' confining to medical treatments and not welcoming patients' questions, or their indifference to concerns and questions of patients was the most important barrier to reaching correct and reliable health information. Participant 3 said "The physician behaved such that I could not ask questions. Well, when he was always writing prescriptions, it means I should not ask any more questions. He saw my MRI and examined me. But I had some questions as well, which left unanswered". Some participants expressed some experiences of their questions deemed unimportant by health professionals and lack of attention to their stresses caused by being in an uncertain situation. A woman explained: "My sister was hospitalized and was to be operated. I was worried and asked her physician many questions. He said why do you ask so many questions? I said I wanted to know about her disease. He said he did not have time to spend an hour to answer my silly questions" (participant 3). Some participants believed that avoiding providing patients with information in young and recently graduated health providers is because of their inexperience and practical and scientific inadequacy. Participant 10 said "Unfortunately, our young physicians only have qualifications; they easily cross their eyebrows and whitewash it. They do not

\begin{tabular}{|c|c|c|c|c|c|c|}
\hline Participant & Age & Education & Health status & Occupation & $\begin{array}{c}\text { Place of resi- } \\
\text { dence }\end{array}$ & Interview location \\
\hline P1 & 50 & Illiterate & Patient & Housewife & City & Participant's home \\
\hline P2 & 47 & Master's & Healthy & Employee & City & Researcher's workplace \\
\hline P3 & 40 & Bachelor's & Healthy & Employee & City & Participant's home \\
\hline P4 & 25 & High school diploma & Healthy & Housewife & City & Researcher's workplace \\
\hline P5 & 50 & High school diploma & Healthy & Employee & City & Researcher's workplace \\
\hline P6 & 40 & Associate Diploma & Healthy & Employee & Village & Researcher home \\
\hline P7 & 30 & High school diploma & Healthy & Housewife & Village & Researcher's workplace \\
\hline P8 & 60 & Religious education & Patient & Housewife & Village & Researcher's workplace \\
\hline P9 & 51 & Bachelor's & Patient & Employee & City & Researcher's workplace \\
\hline P10 & 55 & High school diploma & Patient & Self-employed & City & Researcher's workplace \\
\hline P11 & 35 & Bachelor's & Healthy & Employee & City & Researcher's workplace \\
\hline P12 & 37 & Religious education & Patient & Housewife & Village & Researcher's workplace \\
\hline P13 & 50 & Associate diploma & Healthy & Employee & City & Researcher's workplace \\
\hline P14 & 38 & Bachelor's & Healthy & Employee & City & Researcher's workplace \\
\hline P15 & 52 & Bachelor's & Patient & Self employed & Village & Researcher's workplace \\
\hline P16 & 51 & High school diploma & Healthy & Employee & City & Participant's workplace \\
\hline P17 & 35 & Master's & Healthy & Employee & Village & Participant's workplace \\
\hline
\end{tabular}


give you the right information. I have come to believe that they do not have sufficient and useful information or think well it is an old woman, so I can say anything right or wrong. I have witnessed all these, and I am so angry. However, we have a lot of experienced old physicians and pharmacists. They are very knowledgeable and patient and explain things nicely. I enjoy asking them questions". In experiences of participants, another cause of inadequate support for health information seeking behaviors was health professionals' poor communication skills, lack of personalized information and their lack of familiarity with local culture. In this regard, a participant stated "Sometimes, some physicians do not even raise their heads to make eye-to-eye contact with patient, while this is very important in obtaining information" (participant 9). Regarding ease of seeking health information from local health professionals, participant 15 said "Local physicians can provide much better consultation, since they know mental, cultural and social conditions of people better".

\subsubsection{Conditions Governing Provision of Health Services}

Sometimes lack of a holistic perspective in health system makes health professionals view patients' problems from their own specialized angle, resulting in failure to provide comprehensive and applicable health information for dealing with complex multidimensional health issues. Moreover, absence of a referral system and lack of health specialists lead to overcrowding and congestion of specialized clinics and offices, especially in public centers, which leaves no opportunity for expression of information seeking behaviors. In this respect, the third participant argued: "As you know, with 70 patients queuing, physicians cannot spend much time with a patient. It took six minutes from the time I entered physician's office until I came out; how could I ask all the questions in my mind in six minutes" (Participant 3). Some women experienced seeking health information as entering physician's domain, and asking for accurate health information as destroying physician's sense of dominance over patients, and subsequently their confrontational attitude against health information seeking behaviors. The 11th participant stated: "About 2 to 3 years ago I took my old father to a physician, and when I began to speak in a scientific language, he confronted me and said that I should not have given medical diagnosis. I do not know, perhaps he felt undermined, or maybe it was his pride. He did not like anyone interfering in his work. Perhaps, he did not like me entering his professional domain".

\subsection{Shame and Embarrassment}

The main information, about which women considered embarrassment as a barrier to seeking, was in the area of obstetrics, gynecology, genitourinary diseases and sexual health. Participant 8, an elderly experienced woman, stated "Despite my age, I still feel embarrassed to visit gynecologists and obstetricians to obtain information. I feel as if a stranger has invaded my most private zone". Regarding shame and embarrassment to ask questions about sexual needs, participant 9 said "A lot of times I have questions about sexual issues, but because of embarrassment, I had to suppress them. Sexual needs are part of essential human needs. No one has ever given us any guidance and we were too shy to ask". Forgoing receiving health information due to embarrassment and shame, some women discontinued treatment, endured pain and suffering, and ultimately experienced psychological harm and marital discord. Participant 10 asserted "The result is continued problems and a cold relationship between us. We cannot talk comfortably about any issue, and it all ends in fighting. Many of our needs remain unanswered. We do not understand each other, it is a like an emotional divorce". Participants expressed several methods for management of information including seeing non-professional people, or finding information in books or magazines. Naturally, information from such sources is often unprofessional, wrong, incomplete, irrelevant and out-of-date.

\subsection{Costs}

Another barrier to seeking health information, especially from official sources by low income women was reported high costs. These costs included transportation costs, especially from rural to urban areas or traveling to larger cities, health professionals' fees, medication, paraclinical and diagnostic tests and sometimes purchasing books and magazines and health consultation. Low obligations of insurance companies were also influential in this area. Regarding lack of insurance cover of some low-income people and how they dealt with costs of health information seeking, participant 15 said "I know a woman who may feel sick once or twice daily, and she has many health questions, and she knows she should go to a physician, but she says if she was to go to a general physician and not a specialist, it would cost her 10-12 thousand Tomans, plus her taxi fare and medication cost, so she cannot afford all that". Regarding costs and low obligations of insurance companies, participant 6 , from a village revealed "When there is a problem, we self-medicate. Visiting a physician costs $20-25$ thousand Tomans each time plus commuting costs and problems and insurance share is almost nothing".

\subsection{Wrong Ideas and Beliefs}

A common belief among participants was stated as: "Likelihood of contracting disease if they sought information about it". Consequently, they avoided thinking and seeking information about critical health issues, including incurable diseases and especially screening for common cancers in women, and seeking information about them. Participant 15 said "Sometimes I think, if I had not asked about it, it would not happen to me". Thus, 
sometimes women expressed fear of contracting disease as a barrier to seeking health information. Participant 5 explained "I am afraid of diseases and always pray to God that it would not happen to me. Whatever you think about, happens to you". Among women's experiences, sometimes over optimism about health was a barrier to seeking health information. The reason given by one of the women about not seeking information on prenatal care was "I did not seek information much. In fact I had not taken pregnancy seriously, and I was very optimistic. I thought it was not very important. When I faced with problems, I realized I should not have been so optimistic". Some women suggested despair, lack of motivation and negative past experiences as barriers to seeking health information. Participant 12 said "Sometimes the information you obtain diminishes your ability to adapt and makes you frustrated". Participant 4 said "Let it be, whatever God wills, it will be. One of the reasons why I do not seek health information is that I have never had good results. On the contrary, results have been negative".

\subsection{Inadequate Health Literacy}

Inability to recognize the need and health information resources, and understanding language of health and applying it in daily life, which all relate to health literacy, were also among important barriers to women's health information seeking. A participant told an anecdote about a woman visiting by a physician: "I was in physician's office with a middle-aged woman. She did not have much information about her disease, and physician was teaching her what she had to do to arrest progress of her disease. Nonetheless, since she did not have adequate knowledge about her disease, she could not understand the physician, and did not ask either". Some women talked about lack of familiarity with reliable sources and centers for specific information. For instance, participant 10 revealed "I do not even know to whom I should go. Somewhere I feel comfortable to explain my problem or I could trust to ask my questions" (Participant 11). Sometimes, the need is recognized and information is requested, but there is a problem in understanding information provided by health professionals. Participant 17 said "Seizure immediately after birth was recorded in my daughter's file. When I asked the physician, I did not receive a convincing answer. He was talking to students about this, but I could not understand what they were saying at all. Nurses did not give me clear answers either, and some of their words were in English, which I could not understand".

\section{Discussion}

The present study results provided a broader and newer insight into barriers to Iranian women's health information seeking. It can be inferred from experiences of participating women in this study that seeking information is often actively formed in the event of health problems. On other occasions, health information is rather obtained passively and accidentally than actually being sought, and visiting health service providers at onset of health risk or a while afterwards, and obtaining information from non-professional sources such as family, friends and associates, or peers and informed people happens, depending on the severity of perceived need to seek information. However, despite preferences of women to seek information from health professionals, their search is predominantly challenged by lack of adequate support from healthcare providers due to factors associated with performance of healthcare providers or conditions governing provision of health services. Although previous studies conducted in Iran report massive workload of healthcare providers, their inability to communicate with patients, inadequate clinical supervision, lack of incentive in healthcare providers and lack of personalized information (21), results of studies conducted in other societies, occasionally report similar circumstances (22, $31,32)$. Therefore, the need to consider this important issue is emphasized in most reports $(19,33,34)$. These results suggest a conflict between patients' expectations and requirements and health system plans and assumptions, such that they have been less successful in achieving client satisfaction, meeting their needs or providing client-oriented services. Undoubtedly, one of the main reasons is failure of health plans and policies to comply with cultural beliefs, values and social structures of any society. Thus, changes in health system structure and health professions training toward providing culture and client-oriented services, emphasizing on effective interpersonal communication skills and establishment of interdisciplinary cooperation to provide integrated care, respect patients' concerns and their participation in medical decisions, and encouragement to self-care seem profoundly necessary. Shame and embarrassment to seek some health information about sensitive issues, difficult to discuss with other, was also expressed as an important barrier to health information seeking behaviors. These results are similar to reports by other studies with different context and cultures (31, 35-37). As discussed, it seems health systems should be encouraged to find a way in which patients' desires, capabilities and religious-cultural limitations are more respected while providing health information. In the present study, high costs of health care and negligible support from insurance organizations were important barriers to health information seeking behaviors, especially among rural women at lower socioeconomic status. Reports from other studies also confirm this $(31,38)$. Although women from low socioeconomic groups have greater need for seeking and obtaining health information (35), they are less involved in information seeking behaviors (24). Inequity in health information has been reported among challenges to this group, especially in rural areas $(39,40)$. Development of health education programs through local media and matching contents of these programs with evidence-based approaches and society needs can pro- 
vide an effective strategy to support information needs of people from lower social classes. The present study results showed lack of access to information and limited health literacy as another barrier to seeking health information. In most studies, the internet is proposed as a fast, cheap and available source for obtaining health information, especially for low-income groups (41). However, given most Iranians' lack of knowledge of English language (38), limited information and health literacy $(35,39)$, lack of access to high speed internet $(42,43)$ and lack of credible educational sites in Persian providing information in simple and usable language for the public (44), visiting health professionals and focusing on physicians was revealed as the most important source for obtaining valid health information (45). Unfortunately, despite high costs and poor performance of health system, patients' access to such information sources is limited. Reform in education programs of healthcare professions and empowerment of graduates to support personal, social, economic, cultural-religious needs of patients, and their involvement in health care and shifting people to other health professions rather than physicians such as nurses and midwives as rich, cheap and available sources of health information can provide an effective strategy to overcome many of barriers to health information seeking behaviors. There is no doubt that development of community-based health education programs is the least expensive and most practical way to meet clients, especially women's information needs, so that people can obtain health information from local specialists (preferably women) with least expenditure of time and money. Although, in some circumstance, old beliefs have been proposed as a valuable source for modern medicine (39), according to the present study results, it can be asserted that sometimes some common superstitious beliefs among people can be a barrier to seeking or access to health information. Entry of health education programs into religious and cultural ceremonies, through educating key people, and using them in health education programs, with a community-based approach, can provide a useful way to reform people's beliefs. This study was conducted for the first time in Iran and the results revealed the need for empowering women by health information. It seems that using triangulation strategy in data gathering and data analysis and also in-depth interviews and prolonged engagement of researchers with participants produced reliable data and led to extracting valid results. Although researchers attempted to ensure the accuracy and reliability of qualitative data, this study was conducted in Rafsanjan city and on middle aged married women, so despite similarity to other places in Iran, generalization of results is limited (like other qualitative studies). Therefore, it is necessary to repeat the study in different groups and cultural backgrounds. Despite global acceptance that supporting women's health information plays an important role in promotion of individual, family and community health, the present study indicated pres- ence of personal, socio-economic and cultural barriers to emergence of their health information seeking behaviors. Unfortunately, most of these barriers are associated with weakness in health system policies. Thus, it shows the need to adopt more comprehensive and complete approaches to provide health information based on cultural, social and economic factors, in which consideration is given to respect religious and cultural beliefs and convictions, and personal and socio-economic capabilities, with contents and method of proving information based on requirements and satisfaction of clients. Furthermore, improving people's health literacy and establishment of local women's health sites and centers to provide community-based, reliable, available and simple health information, and considering sensitivity of contents of programs to culture and religion, in such a format to reflect people's beliefs and values, can be effective measures in removing such barriers.

\section{Acknowledgements}

This study was supported by the research deputy of Kerman University of Medical Sciences. The authors appreciate all participants for sharing their experiences about health information seeking.

\section{Authors' Contributions}

Tayebeh Negahban Bonabi designed the research, conducted the interviews and data analysis, and prepared the first draft of the manuscript. Alireza Nikbakht Nasrabadi was as a supervisor in all stages of research, especially analyzing data and preparing the final version of manuscript. Sakineh Sabzevari was a consultant in research process.

\section{Funding/Support}

Kerman University of Medical Sciences funded this study.

\section{References}

1. Marmot M, Commission on Social Determinants of H. Achieving health equity: from root causes to fair outcomes. Lancet. 2007;370(9593):1153-63.

2. Stewart JC, Perkins AJ, Callahan CM. Effect of collaborative care for depression on risk of cardiovascular events: data from the IMPACT randomized controlled trial. Psychosom Med. 2014;76(1):29-37.

3. Skinner TC, Bruce DG, Davis TM, Davis WA. Personality traits, selfcare behaviours and glycaemic control in type 2 diabetes: the Fremantle diabetes study phase II. Diabet Med. 2014;31(4):487-92.

4. Evans-Hudnall GL, Stanley MA, Clark AN, Bush AL, Resnicow K, Liu Y, et al. Improving secondary stroke self-care among underserved ethnic minority individuals: a randomized clinical trial of a pilot intervention.J Behav Med. 2014;37(2):196-204.

5. Chen Y, Feeley TH. Numeracy, information seeking, and selfefficacy in managing health: an analysis using the 2007 Health Information National Trends Survey (HINTS). Health Commun. 2014;29(9):843-53.

6. Johnson JD. On contexts of information seeking. Inf Proc Manag. 2003;39(5):735-60. 
7. healthypeople.gov.. Healthy People 2020 framework: the vision, mission and goals of Healthy People 2020. Washington, DC: US Department of Health and Human Services, Federal Interagency Workgroup; 2012. Available from: http://www.healthypeople. gov/2020/Consortium/HP2020Framework.pdf.

8. Lambert SD, Loiselle CG. Health information seeking behavior. Qual Health Res. 2007;17(8):1006-19.

9. Nicholas D, Huntington P, Williams P, Blackburn P. Digital health information provision and health outcomes. J Inf Sci. 2001;27(4):265-76.

10. Cutilli CC. Seeking health information: what sources do your patients use? Orthop Nurs. 2010;29(3):214-9.

11. Rice RE. Influences, usage, and outcomes of Internet health in formation searching: multivariate results from the Pew surveys. Int J Med Inform. 2006;75(1):8-28.

12. Shim M, Kelly B, Hornik R. Cancer information scanning and seeking behavior is associated with knowledge, lifestyle choices, and screening. J Health Commun. 2006;11 Suppl 1(S1):157-72.

13. Conner KO, Copeland VC, Grote NK, Koeske G, Rosen D, Reynolds C3, et al. Mental health treatment seeking among older adults with depression: the impact of stigma and race. Am J Geriatr Psychiatry. 2010;18(6):531-43.

14. Synnot AJ, Hill SJ, Garner KA, Summers MP, Filippini G, Osborne $\mathrm{RH}$, et al. Online health information seeking: how people with multiple sclerosis find, assess and integrate treatment information to manage their health. Health Expect. 2014.

15. Mitchell KJ, Ybarra ML, Korchmaros JD, Kosciw JG. Accessing sexual health information online: use, motivations and consequences for youth with different sexual orientations. Health Educ Res. 2014;29(1):147-57.

16. Hyman I, Gucciardi E, Patychuk D, Rummens JA, Shakya Y, Kljujic $D$, et al. Self-management, health service use and information seeking for diabetes care among Black Caribbean immigrants in Toronto. Can J Diabetes. 2014;38(1):32-7.

17. Blanch-Hartigan D, Blake KD, Viswanath K. Cancer survivors' use of numerous information sources for cancer-related information: does more matter? J Cancer Educ. 2014;29(3):488-96.

18. Kim SC, Shah DV, Namkoong K, McTavish FM, Gustafson DH. Predictors of Online Health Information Seeking Among Women with Breast Cancer: The Role of Social Support Perception and Emotional Well-Being. J Comput Mediat Commun. 2013; 18(2):98-118

19. Alpay L, Verhoef J, Xie B, Te'eni D, Zwetsloot-Schonk JH. Current Challenge in Consumer Health Informatics: Bridging the Gap between Access to Information and Information Understanding. Biomed Inform Insights. 2009;2(1):1-10.

20. Mosavi SA, Babazadeh R, Najmabadi KM, Shariati M. Assessing Iranian adolescent girls' needs for sexual and reproductive health information. J Adolesc Health. 2014;55(1):107-13.

21. Gholami M, Fallahi Khoshknab M, Maddah SS, Ahmadi F, Khankeh H. Barriers to health information seeking in Iranian patients with cardiovascular disease: a qualitative study. Heart Lung. 2014;43(3):183-91.

22. Warner D, Procaccino JD. Toward wellness: Women seeking health information.J America Soc Inf Sci Tech. 2004;55(8):709-30.

23. Shieh C, Broome ME, Stump TE. Factors associated with health information-seeking in low-income pregnant women. Women Health. 2010;50(5):426-42.

24. Wang MP, Viswanath K, Lam TH, Wang X, Chan SS. Social determinants of health information seeking among Chinese adults in Hong Kong. PLoS One. 2013;8(8).

25. Reczek C, Umberson D. Gender, health behavior, and intimate relationships: lesbian, gay, and straight contexts. Soc Sci Med. 2012;74(11):1783-90.
26. Boudioni M, McPherson K, Moynihan C, Melia J, Boulton M, Leydon G, et al. Do men with prostate or colorectal cancer seek different information and support from women with cancer? $\mathrm{Br} \mathrm{J}$ Cancer. 2001;85(5):641-8.

27. Elo S, Kyngas $\mathrm{H}$. The qualitative content analysis process. J Adv Nurs. 2008;62(1):107-15.

28. Hsieh HF, Shannon SE. Three approaches to qualitative content analysis. Qual Health Res. 2005;15(9):1277-88.

29. Pope C, van Royen P, Baker R. Qualitative methods in research on healthcare quality. Qual Saf Health Care. 2002;11(2):148-52.

30. Guba EG, Lincoln YS. Competing paradigms in qualitative research. Handbook of qualitative research. 1994;2:163-94.

31. Rahman SA, Kielmann T, McPake B, Normand C. Healthcareseeking behaviour among the tribal people of Bangladesh: Can the current health system really meet their needs? J Health Popul Nutr. 2012;30(3):353-65.

32. Rutten LJ, Arora NK, Bakos AD, Aziz N, Rowland J. Information needs and sources of information among cancer patients: a systematic review of research (1980-2003). Patient Educ Couns. 2005;57(3):250-61

33. Stavri PZ. Personal health information-seeking: a qualitative review of the literature. Stud Health Technol Inform. 2001;84(Pt 2):1484-8

34. Maibach EW, Weber D, Massett H, Hancock GR, Price S. Understanding consumers' health information preferences: development and validation of a brief screening instrument. $J$ Health Commun. 2006;11(8):717-36.

35. Das A, Sarkar M. Pregnancy-related health information-seeking behaviors among rural pregnant women in India: validating the Wilson model in the Indian context. Yale J Biol Med. 2014;87(3):251-62.

36. Laz TH, Berenson AB. Racial and ethnic disparities in internet use for seeking health information among young women. J Health Commun. 2013;18(2):250-60.

37. McInnes N, Haglund BJ. Readability of online health information: implications for health literacy. Inform Health Soc Care. 2011;36(4):173-89.

38. Dastjerdi M. The case of Iranian immigrants in the greater Toronto area: a qualitative study. Int J Equity Health. 2012;11(9):9.

39. Warren JR, Kvasny L, Hecht ML, Burgess D, Ahluwalia JS, Okuyemi KS. Barriers, control and identity in health information seeking among African American women. J Heal Dispariti Res Pract. 2012;3(3):5.

40. Matthews AK, Sellergren SA, Manfredi C, Williams M. Factors influencing medical information seeking among African American cancer patients. J Health Commun. 2002;7(3):205-19.

41. Borzekowski DL, Fobil JN, Asante KO. Online access by adolescents in Accra: Ghanaian teens' use of the internet for health information. Dev Psychol. 2006;42(3):450-8.

42. Mehdi M, Mahdi S, Arash A. A study of the reasons for shortcomings in establishment of internet financial reporting in Iran. African J Busin Manag. 2011;5(8):3312-21.

43. Ameripour A, Nicholson B, Newman M. Conviviality of Internet social networks: An exploratory study of Internet campaigns in Iran. JInf Tech. 2010;25(2):244-57.

44. Health information need and seeking behavior of patients in developing countries' context; an Iranian experience. In: Gavgani VZ editor. . Proceedings of the 1st ACM International Health Informatics Symposium. 2010 ACM:pp. 575-9.

45. Samadi M, Kahooei F, Gazerani M, Mozaffari Z. The Prioritization of Information Needs Related to Health among Women Who Had Undergone Surgery in Obstetrics and Gynecology Department in Hospitals of Semnan, Iran, 2012-2013. Iran J Mid Infert. 2012;16(63):8-15 